Article

\title{
Enhancement of Hydrogen Storage Behavior of Complex Hydrides via Bimetallic Nanocatalysts Doping
}

\author{
Sesha S. Srinivasan * and Prakash C. Sharma \\ Department of Physics, Tuskegee University, Tuskegee, AL 36088, USA \\ * Author to whom correspondence should be addressed; E-Mail: srinivas@mytu.tuskegee.edu; \\ Tel.: +1-334-727-8996; Fax: +1-334-724-3917.
}

Received: 3 July 2012; in revised form: 28 August 2012 / Accepted: 28 September2012 /

Published: 17 October 2012

\begin{abstract}
Pristine complex quaternary hydride $\left(\mathrm{LiBH}_{4} / 2 \mathrm{LiNH}_{2}\right)$ and its destabilized counterpart $\left(\mathrm{LiBH}_{4} / 2 \mathrm{LiNH}_{2} /\right.$ nanoMgH$\left._{2}\right)$ have recently shown promising reversible hydrogen storage capacity under moderate operating conditions. The destabilization of complex hydride via nanocrystalline $\mathrm{MgH}_{2}$ apparently lowers the thermodynamic heat values and thus enhances the reversible hydrogen storage behavior at moderate temperatures. However, the kinetics of these materials is rather low and needs to be improved for on-board vehicular applications. Nanocatalyst additives such as nano $\mathrm{Ni}$, nano $\mathrm{Fe}$, nano $\mathrm{Co}$, nano $\mathrm{Mn}$ and nano $\mathrm{Cu}$ at low concentrations on the complex hydride host structures have demonstrated a reduction in the decomposition temperature and overall increase in the hydrogen desorption reaction rates. Bi-metallic nanocatalysts such as the combination of nano $\mathrm{Fe}$ and nano $\mathrm{Ni}$ have shown further pronounced kinetics enhancement in comparison to their individual counterparts. Additionally, the vital advantage of using bi-metallic nanocatalysts is to enable the synergistic effects and characteristics of the two transitional nanometal species on the host hydride matrix for the optimized hydrogen storage behavior.
\end{abstract}

Keywords: bimetallic nanocatalysts; hydrogen storage; desorption kinetics; catalyst doping; pressure-composition isotherms 


\section{Introduction}

Complex hydrides composed of elements with less than an average molecular weight of $51.8 \mathrm{~g} / \mathrm{mol}$ (Cr) provide a sufficient enough gravimetric hydrogen density to meet or exceed the Department of Energy (DOE) targets for a practical hydrogen storage system. Group I, II and III light metals, such as $\mathrm{Li}, \mathrm{K}, \mathrm{Be}, \mathrm{Na}, \mathrm{Mg}, \mathrm{B}, \mathrm{Ca}$ and $\mathrm{Al}$ are considered to be excellent candidates and they form a large variety of metal hydrogen complexes [1-5]. The most common of these metal hydrogen complexes consists of alanates $\left(\mathrm{AlH}_{4}{ }^{-}\right)$, borohydride $\left(\mathrm{BH}_{4}{ }^{-}\right)$, amide $\left(\mathrm{NH}_{2}{ }^{-}\right)$ions which are accompanied by cations such as $\mathrm{Li}^{+}$or $\mathrm{Na}^{+}$. The hydrogen is generally stored in the corners of a tetrahedron within these systems.

Most alanates are extremely stable and often decompose in two- or three- step reactions, limiting the amount of hydrogen that can be released, since often a higher temperature is required for the release of hydrogen from the second step. Borohydrides are also extremely stable and therefore often require high temperatures for hydrogen release, but do so in one-step reactions, thereby eliminating the need for extremely high temperatures also increase the kinetics of hydrogen release.

Lithium borohydride $\left(\mathrm{LiBH}_{4}\right)$ and lithium amide $\left(\mathrm{LiNH}_{2}\right)$ were chosen as the two primary hydride materials for the preparation of novel complex quaternary hydride $\left(\mathrm{LiBH}_{4} / 2 \mathrm{LiNH}_{2}\right)$ because of their high gravimetric hydrogen densities. $\mathrm{LiBH}_{4}$ has been studied extensively for its chemical properties as well as its hydrogen storage characteristics. It has been demonstrated that $\mathrm{LiBH}_{4}$ possesses an orthorhombic crystal structure [6]. The gravimetric hydrogen density of $\mathrm{LiBH}_{4}$ is 18.5 wt.\%, significantly more than the material requirements set forth by the US DOE and FreedomCAR. While hydrogen is generally not released until above $470{ }^{\circ} \mathrm{C}$ [7], it was found that additives can reduce the hydrogen release temperature to as low as $200{ }^{\circ} \mathrm{C}$, as is the case for $\mathrm{SiO}_{2}$ [8], but the kinetics of the reaction is very slow, making this material impractical for hydrogen storage use in automobiles.

As early as 1910, it was found that $\mathrm{Li}_{3} \mathrm{~N}$ reacts with hydrogen to form $\mathrm{LiNH}_{2}$ [9], though $\mathrm{LiH}$ is also formed as a by-product. $\mathrm{LiNH}_{2}$ has a theoretical hydrogen capacity of $8.1 \mathrm{wt} . \%$ and releases hydrogen after melting at a temperature of $380{ }^{\circ} \mathrm{C}$. While the temperature is too high for hydrogen release, there has been significant improvement in the hydrogen storage behavior of $\mathrm{LiNH}_{2}$ by using either catalysts to reduce the hydrogen release temperature or by destabilizing $\mathrm{LiNH}_{2}$ with other compounds such as $\mathrm{MgH}_{2}$. Additionally, the release of ammonia $\left(\mathrm{NH}_{3}\right)$ poses a large problem since $\mathrm{NH}_{3}$ can poison the fuel cells. However, the formation of ammonia can be suppressed through the addition of either catalysts or by destabilizing $\mathrm{LiNH}_{2}$ with other compounds. It was shown, for example, that the addition of $\mathrm{LiH}$ to $\mathrm{LiNH}_{2}$ can suppress any ammonia formation due to the $\mathrm{LiH}$ reacting with $\mathrm{NH}_{3}$, which is a very fast reaction [10]. Furthermore, the temperature of hydrogen release of $\mathrm{LiNH}_{2}$ has been reduced to approximately $150-250{ }^{\circ} \mathrm{C}$ through the addition of $\mathrm{TiCl}_{3}$ [11]. Many researchers have been reported complex hydrides for hydrogen storage, the most important and recent of which are summarized elsewhere [8,12-37].

While it appears that there are several materials that would meet the DOE guidelines, the amidoborane compounds [33], such as $\mathrm{LiNH}_{2} \mathrm{BH}_{3}$ or $\mathrm{NaNH}_{2} \mathrm{BH}_{3}$ are non-reversible, thereby making the systems impractical for mobile use. On the other hand, $\mathrm{Mg}\left(\mathrm{NH}_{2}\right)_{2}+2 \mathrm{MgH}_{2}$ was found to release 7.6 wt.\% around room temperature during ball milling [15], but exhibited such a low enthalpy that a high pressure would be required to rehydrogenate the material, thereby also making the material 
impractical for use as a reversible hydrogen storage system. A promising system for hydrogen storage has been magnesium amide $\left(\mathrm{Mg}\left(\mathrm{NH}_{2}\right)_{2}\right)$ with a capacity of between $5.6 \mathrm{wt} \%$ and $9.2 \mathrm{wt} . \%[21,24,36]$, though all of these systems require temperatures of close to $200{ }^{\circ} \mathrm{C}$ with a reduction in capacity directly proportional to the reduction in temperature.

By combining the advantages of some of these systems, namely the borohydride family of materials with the magnesium amide systems, it is thought that a combinatorial effect can be achieved with a reduction in hydrogen sorption temperature, reversibility, as well as a high hydrogen capacity. The overall goal of the investigation of complex hydrides for hydrogen storage is to reduce the hydrogen release temperature, which can be accomplished by either reducing the particle size, as is the case for $\mathrm{MgH}_{2}$, or by destabilizing the material through the addition of catalysts or other additives. Ball milling is the chosen processing technique, as this combines both chemical and mechanical synthesis of the material. By ball milling, a homogeneous mixture with reduced particle size can be achieved. The parent compounds are combined in the ball mill container and through milling at high speeds, the materials grind each other down to smaller particle size and produce a homogeneous mixture, possibly with a new chemical composition.

Magnesium hydride, $\mathrm{MgH}_{2}$, has a theoretical hydrogen capacity of $7.6 \mathrm{wt} . \%$, an ideal value for practical hydrogen storage applications. However, a temperature of 350 to $400{ }^{\circ} \mathrm{C}$ is required to release hydrogen from this material. Additionally, the kinetics of release and uptake of hydrogen are too slow for practical use [38]. It was found that hydrogen pressure change on $\mathrm{MgH}_{2}$ is the driving force for hydrogen absorption [39]. This means that a higher pressure leads to a higher rate of absorption of hydrogen by pure magnesium. However, a limiting factor in the rate of hydrogen, as well as the final capacity of hydrogen absorbed, is the formation of a surface shell of magnesium hydride, essentially a diffusion barrier layer which prevents any further hydrogen uptake. This is found to be the case especially for pressures above 30 bars, where the rate of hydrogen uptake is found to be a maximum [39]. The hydrogen absorption kinetics was found to be controlled by diffusion of hydrogen atoms [40], especially the diffusion of hydrogen in the hydride-metal interface. If the hydride layer exceeds 30 to $50 \mu \mathrm{m}$, hydrogen diffusion, and therefore uptake, is found to decrease due to the coalescence of the hydride nuclei on the magnesium surface which forms a compact hydride layer [41].

In order to prevent this passivation layer, which not only slows the uptake of hydrogen, but also prevents full hydrogenation of the magnesium, the particle size of $\mathrm{MgH}_{2}$ can be reduced so as to prevent the formation of this hydride layer. If the particles are smaller than $30 \mu \mathrm{m}$, the hydrogen diffusion should therefore be able to continue, allowing for more rapid and full hydrogen uptake of magnesium. As already mentioned, the use of ball milling allows for the reduction of particle sizes. Hence, we have investigated the correlation between particle size reduction and thermal properties of $\mathrm{MgH}_{2}$ that resulted from this purely physical aspect of mechano-chemical synthesis. In order to keep the $\mathrm{MgH}_{2}$ hydrogenated, the sample was purged using ultra high purity hydrogen gas for at least $15 \mathrm{~min}$ in between every $2 \mathrm{~h}$ of milling process.

Solid state synthesis pertaining to the destabilization of $\mathrm{LiBH}_{4}$ and $\mathrm{LiBH}_{4} / \mathrm{LiNH}_{2}$ [42] with $\mathrm{MgH}$ has been found to enhance the reversible hydrogen storage characteristics. The multinary complex hydride $\mathrm{LiBH}_{4} / 2 \mathrm{LiNH}_{2} / \mathrm{MgH}_{2}$ (Li-Mg-B-N-H) possesses a theoretical hydrogen capacity of approximately 8 to $10 \mathrm{wt} . \%$. However, it has been reported that only about $3 \mathrm{wt} . \%$ of hydrogen was 
reversibly released between $160-200{ }^{\circ} \mathrm{C}[43,44]$. It was reported that the $\mathrm{MgH}_{2}$ acts as a catalyst and assists in self-catalyzing the material to release hydrogen with three main reactions:

$$
\begin{gathered}
\sim 175^{\circ} \mathrm{C}: 2 \mathrm{Li}_{4} \mathrm{BN}_{3} \mathrm{H}_{10}+3 \mathrm{MgH}_{2} \rightarrow 3 \mathrm{Li}_{2} \mathrm{Mg}(\mathrm{NH})_{2}+2 \mathrm{LiBH}_{4}+6 \mathrm{H}_{2} \\
\sim 200{ }^{\circ} \mathrm{C}: \mathrm{Mg}\left(\mathrm{NH}_{2}\right)_{2}+2 \mathrm{LiH} \rightarrow \mathrm{Li}_{2} \mathrm{Mg}(\mathrm{NH})_{2}+2 \mathrm{H}_{2} \\
\sim 300^{\circ} \mathrm{C}: 3 \mathrm{Li}_{2} \mathrm{Mg}(\mathrm{NH})_{2}+2 \mathrm{LiBH}_{4} \rightarrow 2 \mathrm{Li}_{3} \mathrm{BN}_{2}+\mathrm{Mg}_{3} \mathrm{~N}_{2}+2 \mathrm{LiH}+6 \mathrm{H}_{2}
\end{gathered}
$$

Keeping these aspects in view, the current study aims to combine several materials, such as $3 \mathrm{~d}$ transition elements/compounds as efficient catalysts and alkali/alkaline hydrides as destabilizers. The activation energy for hydrogen release or absorption can be altered and thus enhance the hydrogenation and dehydrogenation behavior of the multinary complex hydrides at low temperatures. When a material is destabilized, it can react with the additive during dehydrogenation to form a new compound, one that requires a lower energy. In this paper, various nano additives such as nano $\mathrm{Ni}$, nano $\mathrm{Fe}$, nano $\mathrm{Co}$, nano $\mathrm{Mn}$ and nano $\mathrm{Cu}$ are investigated for the hydrogen sorption characteristics of multinary complex hydride $\mathrm{LiBH}_{4} / 2 \mathrm{LiNH}_{2} /$ nanoMgH$_{2}(\mathrm{LinMgBNH})$ system.

\section{Results and Discussion}

\subsection{Structural and Chemical Characteristics of Multinary Complex Hydride $\mathrm{LiBH}_{4} / 2 \mathrm{LiNH}_{2} / \mathrm{Nano}$} $\mathrm{MgH}_{2}$ (XRD and FTIR Explorations)

Figure 1 shows the XRD pattern of the parent complex metal hydrides such as $\mathrm{LiBH}_{4}, \mathrm{LiNH}_{2}$ and $\mathrm{MgH}_{2}$, nano $\mathrm{MgH}_{2}$; the as-synthesized quaternary (LiBNH) and multinary (LinMgBNH) systems. The peak around $21^{\circ}$ is from the Parafilm ${ }^{\circledR}$ used to protect the samples during XRD measurements. Neither $\mathrm{LiBH}_{4}$ nor $\mathrm{LiNH}_{2}$ peaks are observed in the as-prepared LiBNH and LinMgBNH complex hydrides. This confirms that these two materials are fully consumed during the milling process and actually form a new quaternary structure, referred to as LiBNH. The quaternary structure has been reported to be $\mathrm{Li}_{4} \mathrm{BN}_{3} \mathrm{H}_{10}$ [26]. When the nano sized $\mathrm{MgH}_{2}$ is added to the quaternary $\mathrm{LiBNH}$, the $\mathrm{MgH}_{2}$ peaks are barely picked up by the XRD. This indicates that the small size of the $\mathrm{MgH}_{2}$ causes the material to intermix and fill voids of the quaternary structure, which results in a nanocrystalline particle distribution, while still preserving the quaternary structure formed by the $\mathrm{LiNH}_{2}$ and $\mathrm{LiBH}_{4}$. The as-synthesized multinary complex hydride is a physical rather than a chemical mixture of the quaternary structure $\mathrm{LiBNH}$ with nano $\mathrm{MgH}_{2}$.

The as-prepared quaternary $(\mathrm{LiBNH})$ and multinary $(\mathrm{LinMgBNH})$ complex hydrides have been characterized using FTIR to obtain information about the B-H and N-H stretches. The data clearly shows (see Figure 2) that the amide $\left(\mathrm{NH}_{2}^{-}\right)$, and borohydride $\left(\mathrm{BH}_{4}{ }^{-}\right)$, anions remain intact, as observed previously for the quaternary LiBNH samples [45]. The peaks of the symmetric and asymmetric amide anions are shifted from the expected 3312 and $3259 \mathrm{~cm}^{-1}$ to 3302 and $3244 \mathrm{~cm}^{-1}$, respectively. Furthermore, the peak around $1560 \mathrm{~cm}^{-1}$ is characteristic of the amide ion (see Figure 2). 
Figure 1. XRD Profiles of the plain $\mathrm{LiBH}_{4}$, plain $\mathrm{LiNH}_{2}, \mathrm{LiBH}_{4} / 2 \mathrm{LiNH}_{2}$ quaternary, commercial $\mathrm{MgH}_{2}$, nano $\mathrm{MgH}_{2}$ and $\mathrm{LiBH}_{4} / 2 \mathrm{LiNH}_{2} /$ nanoMgH$_{2}$ multinary complex hydride.

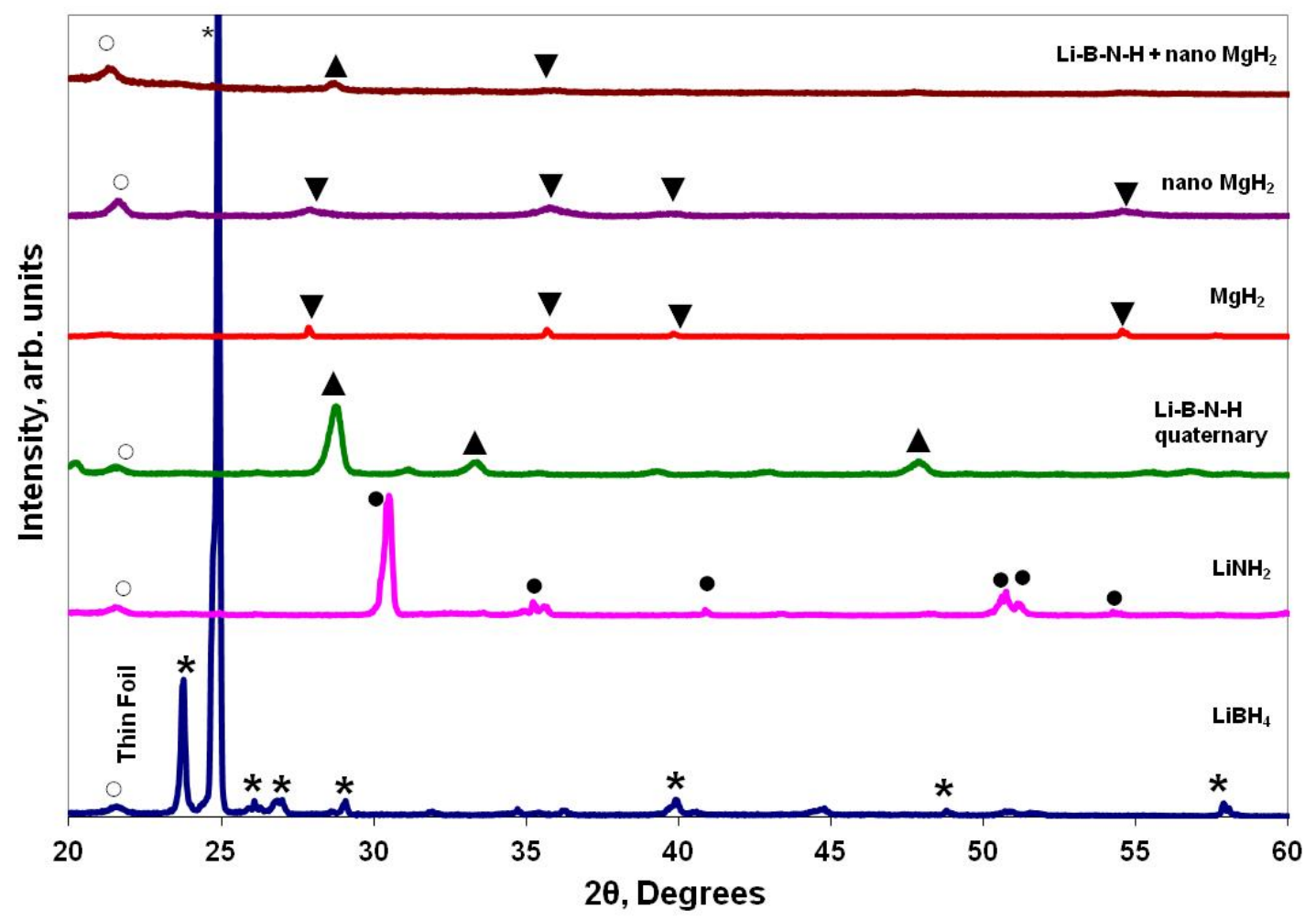

Figure 2. FTIR spectra of the plain $\mathrm{LiBH}_{4}$, plain $\mathrm{LiNH}_{2}, \mathrm{LiBH}_{4} / 2 \mathrm{LiNH}_{2}$ quaternary and $\mathrm{LiBH}_{4} / 2 \mathrm{LiNH}_{2} /$ nanoMgH$_{2}$ multinary complex hydride.

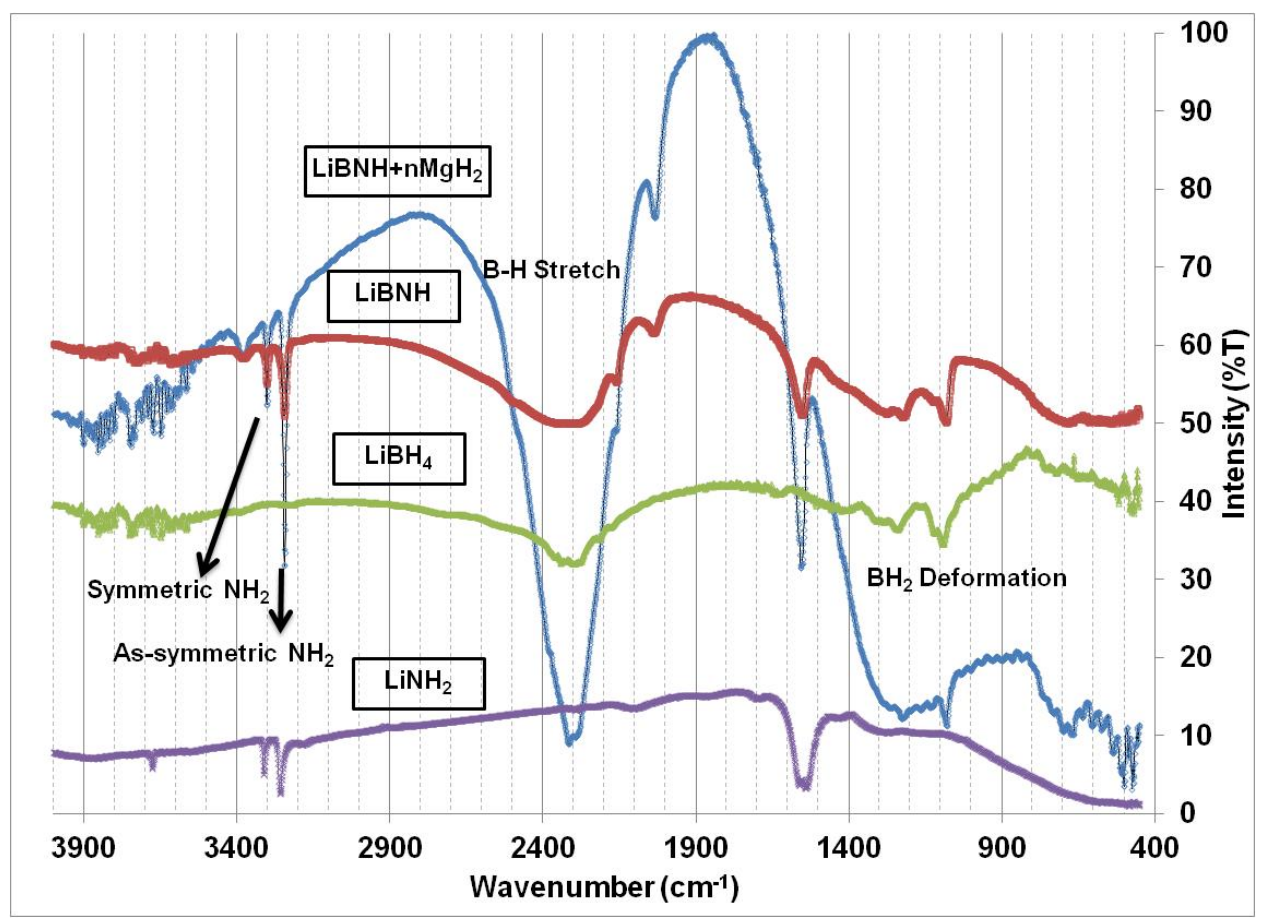

The B-H stretches, usually found at $2225,2237,2293$, and $2387 \mathrm{~cm}^{-1}$, overlap in the samples to form one large $\mathrm{B}-\mathrm{H}$ stretch with a peak around $2320 \mathrm{~cm}^{-1}$. Finally, the $\mathrm{BH}_{2}$ deformation peaks found at 
1120 and $1092 \mathrm{~cm}^{-1}$ in $\mathrm{LiBH}_{4}$ are observed at 1120 and $1082 \mathrm{~cm}^{-1}$, respectively, though the peak around $1120 \mathrm{~cm}^{-1}$ is extremely weak. However, there is no observable shift in any of the main stretches indicating that the chemical composition of the quaternary hydride is kept intact, and there is, in fact, no formation of a new compound other than the previously reported structure [45]. There is no evidence in the FTIR data indicating the reaction of $\mathrm{MgH}_{2}$ with either the amide or borohydride, further confirming the XRD data shown in Figure 1.

\subsection{Thermal Desorption Characteristics of Undoped and Bimetallic Catalysts Doped Multinary Complex Hydrides (LiBnMgNH)}

Thermal Programmed Desorption (TPD) was used to obtain information about changes in the parent material's hydrogen characteristics. Specifically, the temperature of hydrogen release, as well as some general information about the kinetics of hydrogen release can be ascertained from this type of measurement. The peak temperature indicates the optimal hydrogen release temperature, whereas the width of the peak can be used to get insight into the rate at which hydrogen is released, at least qualitatively. A wide peak indicates a low rate of hydrogen release, whereas a narrow and sharp peak indicates rapid hydrogen release. As can be seen from Figure 3, it is clear that all of the additives allow for a lower hydrogen release temperature. It is clearly discernible that the as-synthesized multinary complex hydride, $\mathrm{LiBNH}+n \mathrm{MgH}_{2}$, exhibits a three-step hydrogen release. While the TPD measurements are used for quick-screening the effect of the additives on the hydrogen performance of the material, it can be seen that each additive material either affects the rate of hydrogen release, as depicted by a sharp and narrow peak (especially nano iron), or significantly lowers the temperature required for hydrogen release.

Since the TPD measurements only give an indication of the hydrogen sorption results, ramping kinetic measurements, where approximately $0.1 \mathrm{~g}$ of sample are loaded into the Pressure-CompositionTemperature (PCT) and then ramped at a rate of $1{ }^{\circ} \mathrm{C} / \mathrm{min}$, are performed on all samples. Figure 4 shows the more detailed hydrogen performance of the standard sample, $\mathrm{LiBNH}+n \mathrm{MgH}_{2}$ without any additives, as well as with 2 mol\% of the previously mentioned additives. It becomes clear that while nano cobalt seems promising from the TPD data, it, in fact has such slow kinetics that nano cobalt is no longer of interest as an additive. The kinetics measurements confirms the TPD data in that nano manganese and nano iron have the fastest kinetics, as indicated by the slope of the desorption curves. Furthermore, the significant reduction in hydrogen release temperature of nano nickel is confirmed. It is also noteworthy to mention from Figure 4 that a faster desorption kinetics at lowest temperature was obtained for the multinary complex hydride (LinMgBNH) simultaneously doped with 2 mol\% of both nanoFe and nanoNi. This may be due to the synergistic nature and characteristics of both the $3 \mathrm{~d}$ transition metal nanocatalysts such as nano iron and nano nickel on the complex hydride system.

Figure 5 shows a comparison of the hydrogen release rate and hydrogen release temperature of the complex multinary hydride $\mathrm{LiBNH}+n \mathrm{MgH}_{2}$ without and with $2 \mathrm{~mol} \%$ of nano-sized additives. Since the nano-sized nickel showed the lowest hydrogen release temperature of just under $200{ }^{\circ} \mathrm{C}$ and nano-sized iron showed the highest release rate $(0.2 \mathrm{wt} . \% / \mathrm{min})$ at a comparatively low temperature of $245^{\circ} \mathrm{C}$, these two additives were chosen to be optimized in terms of their concentration. 
Figure 3. TPD profiles comparison of $\mathrm{LiBNH}+n \mathrm{MgH}_{2}$ without additive and with $2 \mathrm{~mol} \%$ nano catalysts such as $\mathrm{Ni}, \mathrm{Cu}, \mathrm{Mn}, \mathrm{Co}$ and $\mathrm{Fe}$ at a constant ramping rate of $1{ }^{\circ} \mathrm{C} / \mathrm{min}$.

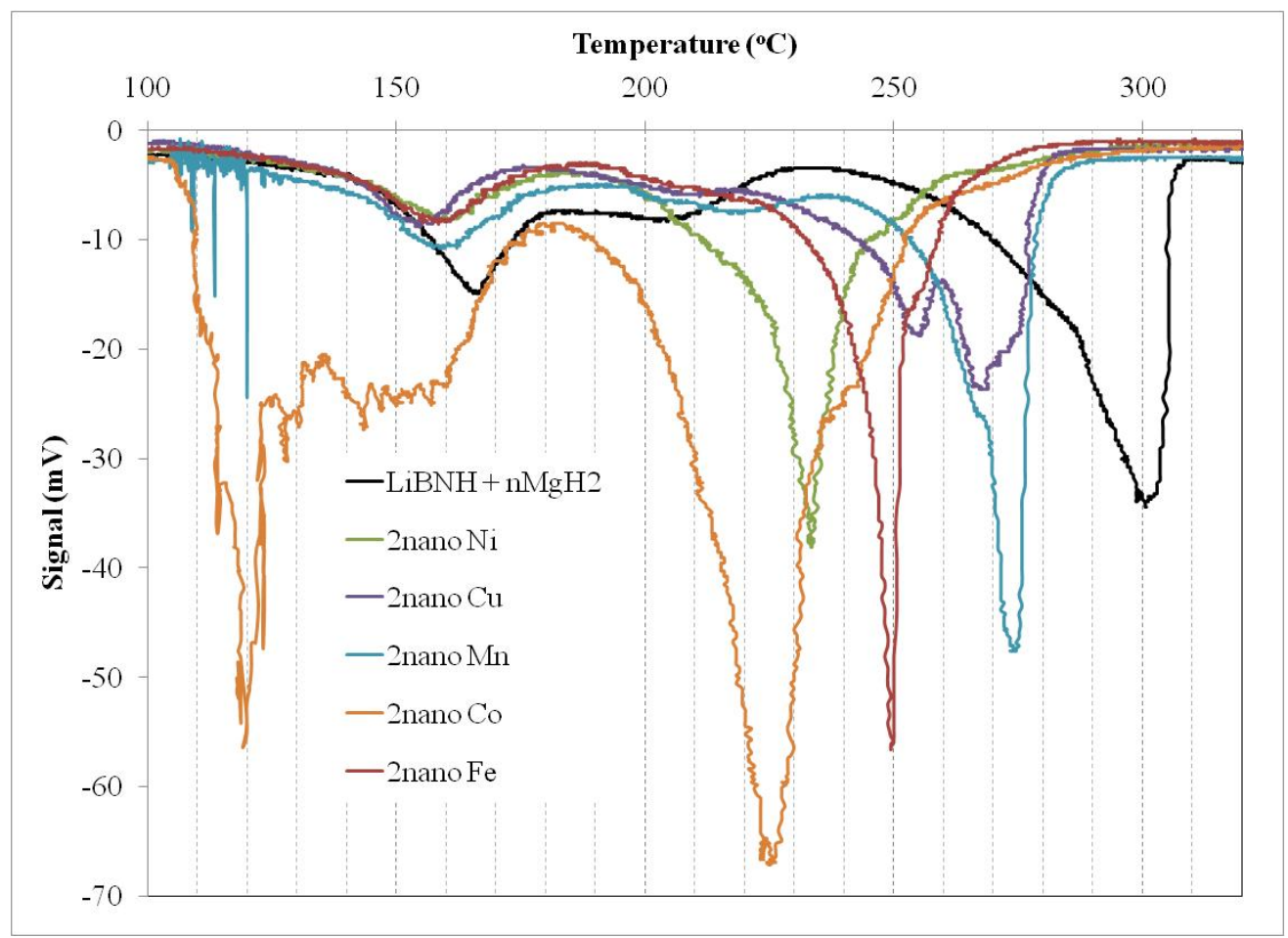

Figure 4. Ramping kinetic measurements of $\mathrm{LiBNH}+n \mathrm{MgH}_{2}$ without and with $2 \mathrm{~mol} \%$ nano catalysts such as $\mathrm{Mn}, \mathrm{Fe}, \mathrm{Co}, \mathrm{Cu}, \mathrm{Ni}$ and $\mathrm{Fe}+\mathrm{Ni}$.

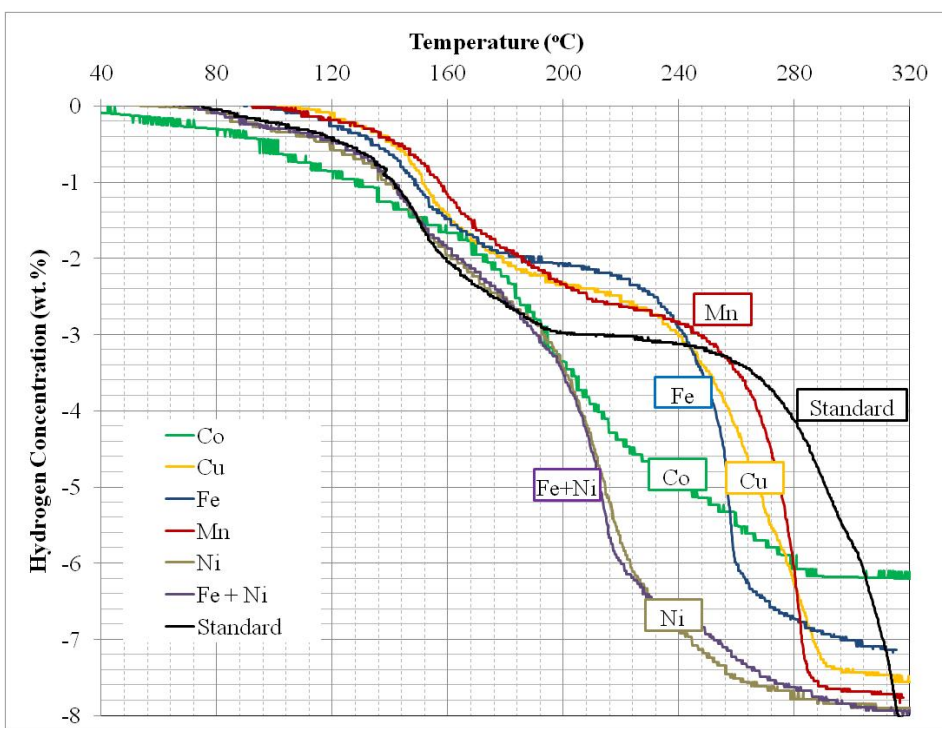

TPD measurements are used to obtain information about the effect of various concentrations of nano nickel and nano iron, but these are not shown here, as the optimum concentration of these additives was investigated for their hydrogen sorption properties. The effect of 2, 4, and $10 \mathrm{~mol} \%$ of nano nickel on the complex hydride material (LinMgBNH) can be seen in Figure 6. While 2 mol\% reduces the hydrogen release temperature as previously mentioned, any further amount of nickel does not further lower this temperature, but instead leads to much slower kinetics of hydrogen release, as is evident by the hydrogen desorption of the standard sample with $10 \mathrm{~mol} \%$ nanoNi. 
Figure 5. Comparison of hydrogen release temperature and hydrogen release rate of the standard $\mathrm{LiBNH}+n \mathrm{MgH}_{2}$ without and with $2 \mathrm{~mol} \%$ of various nano additives.

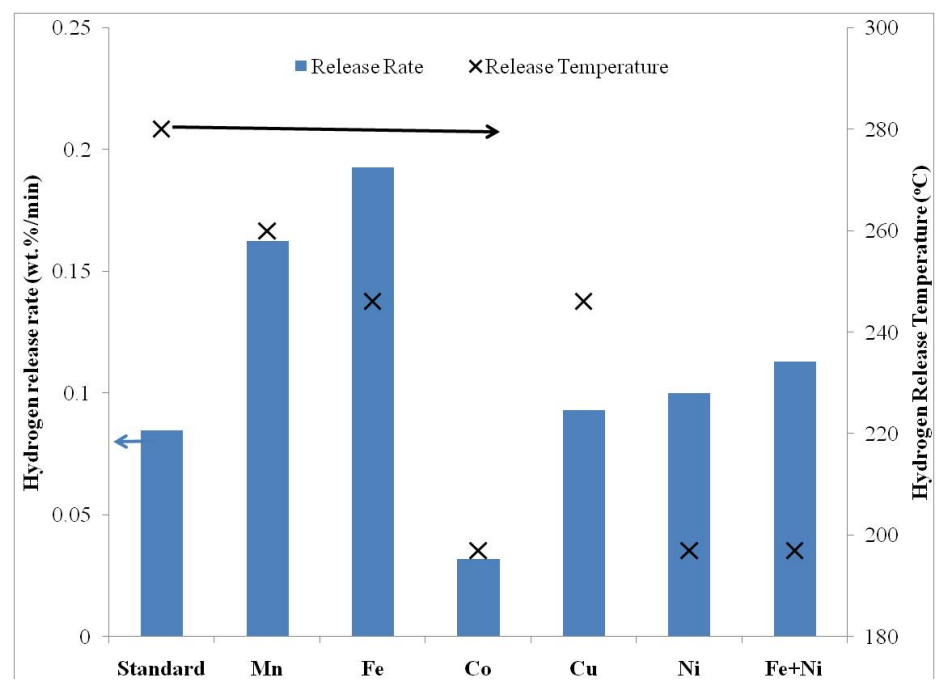

Figure 6. Ramping desorption kinetics of $\mathrm{LiBNH}+n \mathrm{MgH}_{2}$ without and with $2 \mathrm{~mol} \%$, $4 \mathrm{~mol} \%$ and $10 \mathrm{~mol} \%$ nano nickel.

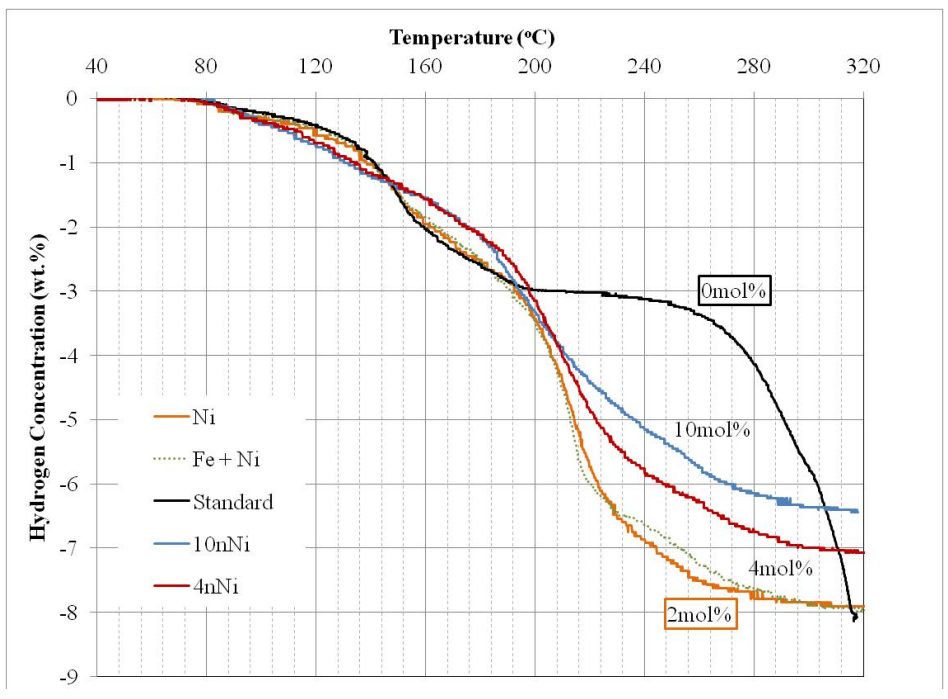

Nano sized iron, on the other hand, maintains its kinetic advantage, but the hydrogen release temperature is further reduced with increasing iron amounts, as seen in Figure 7. A capacity of 6 wt.\% of hydrogen can be achieved with $0.2 \mathrm{wt} . \% / \mathrm{min}$ at a temperature of around $200{ }^{\circ} \mathrm{C}$ for $10 \mathrm{~mol} \%$ nano iron, as compared to $6 \mathrm{wt} . \%$ at $300{ }^{\circ} \mathrm{C}$ at a rate of $0.08 \mathrm{wt} . \% / \mathrm{min}$ without any additive. This is a significant improvement and is most likely due the interaction of iron with magnesium which allows for a rapid hydrogen release at lower temperatures as the iron bonds with the magnesium, thereby forming a magnesium-iron alloy. 
Figure 7. Ramping desorption kinetics comparing $\mathrm{LiBNH}+n \mathrm{MgH}_{2}$ without and with $2 \mathrm{~mol} \%$ and $10 \mathrm{~mol} \%$ nano iron.

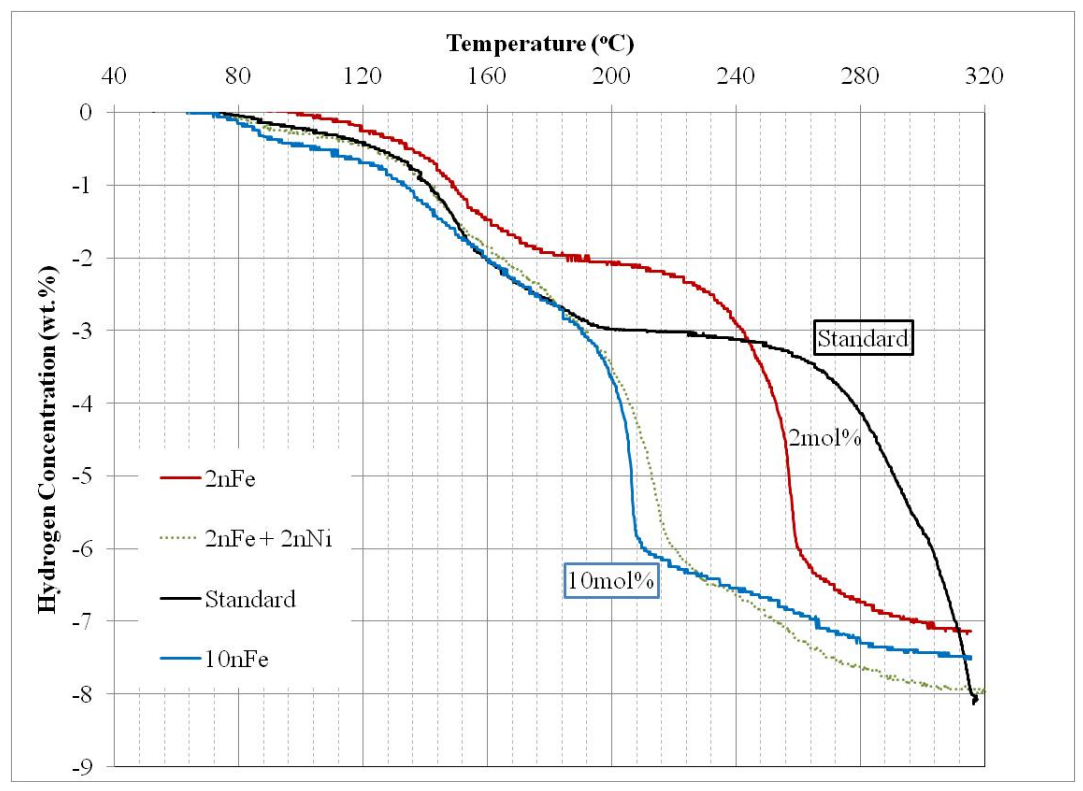

\section{Experimental Section}

\subsection{Synthesis and Nanocatalyst Doping of Complex Multinary Hydrides (LinMgBNH)}

The parent compounds, $\mathrm{LiBH}_{4}$ and $\mathrm{LiNH}_{2}$, were purchased from Sigma Aldrich with a purity of $95 \%$, and $\mathrm{MgH}_{2}$ was obtained from Alfa Aesar with a purity of 98\%. All materials were kept in the inert atmosphere of the glove box and used without further purification. The $\mathrm{MgH}_{2}$ was either added as received or was added as a nano $\mathrm{MgH}_{2}$. The nano $\mathrm{MgH}_{2}\left(n \mathrm{MgH}_{2}\right)$ was created by ball milling the commercial $\mathrm{MgH}_{2}\left(\mathrm{cMgH}_{2}\right)$ for $12 \mathrm{~h}$ with intermittent hydrogen/argon purges every $2 \mathrm{~h}$. This ensured the reduction of particle size as well as the decrease in hydrogen release temperature, as previously reported [38]. The multinary complex hydride (LinMgBNH) was created in $4 \mathrm{~g}$ batch with a constant molar ratio of $2 \mathrm{LiNH}_{2}: \mathrm{LiBH}_{4}: n \mathrm{MgH}_{2}$, while taking into account the purity of the parent compounds, by employing high energy ball milling (Fritsch Pulverisette 6) for $5 \mathrm{~h}$ at $300 \mathrm{rpm}$ with intermittent hydrogen/argon (5\%/95\%) purges for 20 min before milling and after $2 \mathrm{~h}$ and $4 \mathrm{~h}$. This was done to ensure that as little hydrogen as possible was released during the milling process and to reduce the agglomeration of the hydride that occurs when pure hydrogen is used. The processing scheme adopted was to create the quaternary structure $\mathrm{Li}_{4} \mathrm{BN}_{3} \mathrm{H}_{10}$ (referred as $\mathrm{LiBNH}$ ) by milling $\mathrm{LiBH}_{4}$ with $2 \mathrm{LiNH}_{2}$ for $5 \mathrm{~h}$ and then adding nano sized $\mathrm{MgH}_{2}$, after which the quaternary and the nano $\mathrm{MgH}_{2}$ were milled for an additional $5 \mathrm{~h}$. All milling was carried out in an inert atmosphere and the samples were purged with the hydrogen/argon mixture every $2 \mathrm{~h}$.

After the multinary complex hydride was synthesized as described above, various concentrations of nano additives were added to $0.4 \mathrm{~g}$ of sample. The samples were loaded in the glove box and the same stainless steel milling container was used to synthesize catalyst doped multinary complex hydrides. These samples were then purged with the same hydrogen/argon mixture, as previously described, for $15 \mathrm{~min}$ before being milled. Initially, the samples were milled at $300 \mathrm{rpm}$ for $15 \mathrm{~min}$ to compare the effect of the nano additives on the multinary hydride. This milling duration allowed a thorough mixing 
of the parent compound with the nano additive without allowing the two to react and form a novel chemical structure. After a quick screening comparison of the various nano additives available, the samples showed an increase in kinetics and a decrease in hydrogen release temperature. Initially, $2 \mathrm{~mol} \%$ of various nano-sized additives obtained from QunatumSphere Inc., was investigated. The materials available were nickel, copper, manganese, cobalt and iron.

\subsection{Characterization and Hydrogen Sorption Measurements of Catalyzed Multinary Complex Hydrides}

The powder X-ray diffraction of the samples have been carried out by Philips X'pert diffractometer with $\mathrm{CuK} \alpha$ radiation of $\lambda=1.54060 \AA$. The as-milled sample, which shows peaks at the $2 \theta$ angles of $21^{\circ}$ and $23^{\circ}$, are prepared inside the glove box and sealed with Parafilm ${ }^{\circledR}$ tape. Diffraction data are analyzed using PANalytical X'pert Highscore software version 1.0f. Perkin-Elmer Spectrum One Fourier transform infrared (FTIR) spectrometer was utilized to measure the bonding stretches of the complex hydride compound. The working range of the FTIR instrument was between $370-7800 \mathrm{~cm}^{-1}$ and a resolution of $0.5 \mathrm{~cm}^{-1}$. The thermal volumetric desorption (ramping kinetics) was performed using Setaram HyEnergy's PCTPro 2000 and Quantachrome's Autosorb 1C thermal programmed desorption (TPD) equipment to understand the hydrogen desorption characteristics of undoped and nanocatalysts doped multinary complex hydrides.

\section{Conclusions}

Through XRD measurements, it was found that a 2:1 molar ratio of $\mathrm{LiNH}_{2}: \mathrm{LiBH}_{4}$ formed a new quaternary compound after approximately $5 \mathrm{~h}$ of ball milling. The obtained quaternary complex hydride $(\mathrm{LiBNH})$ was further mixed with nano $\mathrm{MgH}_{2}$ and subjected to ball milling under $\mathrm{Ar} / \mathrm{H}_{2}$ $(95 / 5 \%)$ ambient for $5 \mathrm{~h}$. XRD of the as-synthesized complex multinary hydride exhibited peaks from LiBNH and nanoMgH$H_{2}$; however, no signatures of the parent $\mathrm{LiBH}_{4}$ and $\mathrm{LiNH}_{2}$ compounds are observed. The Fourier Transform Infrared Spectroscopy (FTIR) results of the as-prepared complex multinary hydride $(\mathrm{LinMgBNH})$ demonstrated the presence of symmetric and asymmetric $\mathrm{NH}_{2}$ stretches, wide $\mathrm{B}-\mathrm{H}$ stretch and $\mathrm{BH}_{2}$ deformation bands. The thermal desorption profile of the undoped LinMgBNH showed three steps of hydrogen release at temperatures around 150, 200 and $300{ }^{\circ} \mathrm{C}$ respectively. However, much earlier on-set decomposition temperatures have been obtained for the nanocatalyst doped LinMgBNH. Nanocatalyst additives such as nanoNi, nanoFe, nanoCo, nanoMn and nanoCu at low concentrations $(2 \mathrm{~mol} \%)$ on the complex hydride host structure demonstrated a reduction in the decomposition temperature and overall increase in the hydrogen desorption reaction rates. Bi-metallic nanocatalysts such as the combination of nanoFe and nanoNi showed further pronounced kinetics enhancement in comparison to their individual counterparts. One important aspect of the fate of nanocrystalline behavior of both nano $\mathrm{MgH}_{2}$ and nano additives after high temperature sorption treatment was not yet determined and are currently under investigation. 


\section{Acknowledgments}

The authors are grateful to financial support provided by the NSF EAGER Grant \# CBET-1233528. Financial support from the ONR-DURIP, Florida Hydrogen Initiative through University of South Florida, BP Oil Spill grant from Dauphin Island Sea Lab are acknowledged gratefully. The authors thank Adaku Ankumah for her comments. Authors wish to thankfully acknowledge Luther S. Williams and B. Bramwell, for their encouragement and support.

\section{Conflict of Interest}

The authors declare no conflict of interest.

\section{References}

1. Schlesinger, H.I.; Brown, H.C. Metallo Borohydrides. III. Lithium Borohydride. J. Am. Chem. Soc. 1940, 62, 3429-3435.

2. Knacke, O.; Kubaschewski, O.; Hesselmann, K. Thermochemical Properties of Inorganic Substances, 2nd ed.; Springer-Verlag: Berlin, Germany, 1991.

3. Bogdanovic, B.; Brand, R.A.; Marjanovic, A.; Schwickardi, M.; Tölle, J. Metal-doped sodium aluminium hydrides as potential new hydrogen storage materials. J. Alloys Compd. 2000, 302, $36-58$.

4. Sandrock, G.; Thomas, G. The IEA/DOE/SNL on-line hydride databases. Appl. Phys. A 2001, 72 , 153-155.

5. Yvon, K. Complex transition-metal hydrides. Chimia 1998, 52, 613-619.

6. Soulié, J.P.; Renaudin, G.; Cerný, R.; Yvon, K. Lithium boro-hydride $\mathrm{LiBH}_{4}$ : I. Crystal structure. J. Alloys Compd. 2002, 346, 200-205.

7. Stasinevitch, D.S.; Egorenko, G.A. Russ. J. Inorg. Chem. 1968, 13, 341-343.

8. Züttel, A.; Rentsch, S.; Fischer, P.; Wenger, P.; Sudan, P.; Mauron, P.; Emmenegger, C. Hydrogen storage properties of $\mathrm{LiBH}_{4}$. J. Alloys Compd. 2003, 356-357, 515-520.

9. Dafert, F.W.; Miklauz, R. über einige neue Verbindungen von Stickstoff und Wasserstoff mit Lithium. Diese Sitzungsberichte 1910, CXVIII, 981-996.

10. Hu, Y.H.; Ruckenstein, E. Ultrafast Reaction between $\mathrm{LiH}$ and $\mathrm{NH}_{3}$ during $\mathrm{H}_{2}$ Storage in $\mathrm{Li}_{3} \mathrm{~N}$. $J$. Phys.Chem. A 2003, 107, 9737-9739.

11. Ichikawa, T.; Isobe, S.; Hanada, N.; Fujii, H. Lithium nitride for reversible hydrogen storage. $J$. Alloys Compd. 2004, 365, 271-276.

12. Aoki, M.; Miwa, K.; Noritake, T.; Kitahara, G.; Nakamori, Y.; Orimo, S.; Towata, S. Destabilization of $\mathrm{LiBH}_{4}$ by mixing with $\mathrm{LiNH}_{2}$. Appl. Phys. A 2005, 80, 1409-1412.

13. Chen, P.; Xiong, Z.; Luo, J.; Lin, J.; Tan, K.L. Interaction of hydrogen with metal nitrides and imides. Nature 2002, 420, 302-304.

14. Diyabalanage, H.V.K.; Shrestha, R.P.; Semelsberger, T.A.; Scott, B.L.; Bowden, M.E.; Davis, B.L.; Burrell, A.K. Calcium Amidotrihydroborate: A Hydrogen Storage Material. Angew. Chem. Int. Ed. 2007, 46, 8995-8997. 
15. Hu, J.; Wu, G.; Liu, Y.; Xiong, Z.; Chen, P.; Murata, K.; Sakata, K.; Wolf, G. Hydrogen Release from $\mathrm{Mg}\left(\mathrm{NH}_{2}\right)_{2}-\mathrm{MgH}_{2}$ through Mechanochemical Reaction. J. Phys. Chem. B 2006, 110, $14688-14692$.

16. Jeon, E.; Cho, Y. Mechanochemical synthesis and thermal decomposition of zinc borohydride. $J$. Alloys Compd. 2006, 422, 273-275.

17. Yang, A.S.J.; Siegel, D.J.; Halliday, D.; Drews, A.; Carter, R.O., III; Wolverton, C.; Lewis, G.J.; Sachtler, J.W.A.; Low, J.J.; Faheem, S.A.; et al. A Self-Catalyzing Hydrogen-Storage Material. Angew. Chem. Int. Ed. 2008, 47, 882-887.

18. Kim, J.-H.; Jin, S.-A.; Shim, J.-H.; Cho, Y.W. Thermal decomposition behavior of calcium borohydride $\mathrm{Ca}\left(\mathrm{BH}_{4}\right)_{2}$. J. Alloys Compd. 2008, 461, L20-L22.

19. Kim, J.-H.; Jin, S.-A.; Shim, J.-H.; Cho, Y.W. Reversible hydrogen storage in calcium borohydride $\mathrm{Ca}\left(\mathrm{BH}_{4}\right)_{2}$. Scr. Mater. 2008, 58, 481-483.

20. Kojima, Y.; Matsumoto, M.; Kawai, Y.; Haga, T.; Ohba, N.; Miwa, K.; Towata, S.-I.; Nakamori, Y.; Orimo, S.-I. Hydrogen Absorption and Desorption by the Li-Al-N-H System. J. Phys. Chem. B 2006, 110, 9632-9636.

21. Leng, H.Y.; Ichikawa, T.; Hino, S.; Hanada, N.; Isobe, S.; Fujii, H. New Metal-N-H System Composed of $\mathrm{Mg}\left(\mathrm{NH}_{2}\right)_{2}$ and $\mathrm{LiH}$ for Hydrogen Storage. J. Phys. Chem. B 2004, 108, 8763-8765.

22. Chen, Y.; Wang, P.; Liu, C.; Cheng, H.-M. Improved hydrogen storage performance of Li-Mg-N-H materials by optimizing composition and adding single-walled carbon nanotubes. Int. J. Hydrog. Energy 2007, 32, 1262-1268.

23. Nakamori, Y.; Li, H.; Miwa, K.; Towata, S.-I.; Orimo, S.-I. Syntheses and Hydrogen Desorption Properties of Metal-Borohydrides $\mathrm{M}\left(\mathrm{BH}_{4}\right)_{n}(\mathrm{M}=\mathrm{Mg}$, Sc, $\mathrm{Zr}$, Ti, and $\mathrm{Zn} ; n=2-4)$ as Advanced Hydrogen Storage Materials. Mater. Trans. 2006, 47, 1898-1901.

24. Nakamori, Y.; Orimo, S.-I. Destabilization of Li-based complex hydrides. J. Alloys Compd. 2004, 370, 271-275.

25. Orimo, S.-I.; Nakamori, Y.; Eliseo, J.R.; Zuttel, A.; Jensen, C.M. Complex Hydrides for Hydrogen Storage. Chem. Rev. 2007, 107, 4111-4132.

26. Pinkerton, F.E.; Meisner, G.P.; Meyer, M.S.; Balogh, M.P.; Kundrat, M.D. Hydrogen Desorption Exceeding Ten Weight Percent from the New Quaternary Hydride $\mathrm{Li}_{3} \mathrm{BN}_{2} \mathrm{H}_{8}, J$. Phys. Chem. $B$ 2005, 109, 6-8.

27. Soloveichik, G.; Her, J.-H.; Stephens, P.W.; Gao, Y.; Rijssenbeek, J.; Andrus, M.; Zhao, J.-C. Ammine Magnesium Borohydride Complex as a New Material for Hydrogen Storage: Structure and Properties of $\mathrm{Mg}\left(\mathrm{BH}_{4}\right)_{2}-\mathrm{NH}_{3}$. Inorg. Chem. 2008, 47, 4290-4298.

28. Stasinevich, D.S.; Egorenko, G.A. Russ. J. Inorg. Chem. 1968, 13, 341.

29. Stephens, F.H.; Pons, V.; Baker, R.T. Ammonia-borane: the hydrogen source par excellence? Dalton Trans. 2007, doi: 10.1039/B703053C.

30. Marder, T.B. Will We Soon Be Fueling our Automobiles with Ammonia-Borane? Angew. Chem. Int. Ed. 2007, 46, 8116-8118.

31. Vajo, J.J.; Skeith, S.L; Mertens, F. Reversible Storage of Hydrogen in Destabilized $\mathrm{LiBH}_{4} . J$. Phys. Chem. B 2005, 109, 3219.

32. Wu, G.; Xiong, Z.; Liu, T.; Liu, Y.; Hu, J.; Chen, P.; Feng, Y.; Wee, A.T.S. Synthesis and Characterization of a New Ternary Imide $\mathrm{Li}_{2} \mathrm{Ca}(\mathrm{NH})_{2}$. Inorg. Chem. 2007, 46, 517-521. 
33. Xiong, Z.; Yong, C.K.; Wu, G.; Chen, P.; Shaw, W.; Karkamkar, A.; Autrey, T.; Jones, M.O.; Johnson, S.R.; Edwards, P.P.; et al. High-capacity hydrogen storage in lithium and sodium amidoboranes. Nature Mater. 2008, 7, 138-141.

34. Xiong, Z.T.; Hu, J.J.; Wu, G.T.; Liu, Y.F.; Chen, P. Large amount of hydrogen desorption and stepwise phase transition in the chemical reaction of $\mathrm{NaNH}_{2}$ and $\mathrm{LiAlH}_{4}$. Catal. Today 2007, 120, 287-291.

35. Liu, Y.; Liu, T.; Xiong, Z.; Hu, J.; Wu, G.; Chen, P.; Wee, A.T.S.; Yang, P.; Murata, K.; Sakata, K. Synthesis and Structural Characterization of a New Alkaline Earth Imide: $\mathrm{MgCa}(\mathrm{NH})_{2}$. Eur. J. Inorg. Chem. 2006, 2006, 4368-4373.

36. Xiong, G.W.Z.; Hu, J.; Chen, P. Ternary Imides for Hydrogen Storage. Adv. Mater. 2004, 16, $1522-1525$.

37. Xiong, G.W.Z.; Hu, J.; Liu, Y.; Chen, P.; Luo, W.; Wang, J. Reversible Hydrogen Storage by a Li-Al-N-H Complex. Adv. Funct. Mater. 2007, 17, 1137-1142.

38. Zaluska, A.; Zaluski, L.; Ström-Olsen, J.O. Nanocrystalline magnesium for hydrogen storage. $J$. Alloys Compd. 1999, 288, 217-225.

39. Vigeholm, B.; Jensen, K.; Larsen, B.; Pedersen, A.S. Elements of hydride formation mechanisms in nearly spherical magnesium powder particles. J. Less-Common Met.1987, 131, 133-141.

40. Vigeholm, B.; Kjoller, J.; Larsen, B.; Pedersen, A.S. Formation and decomposition of magnesium hydride. J. Less-Common Met.1983, 89, 135-144.

41. Ryden, J.; Hjorvarsson, T.; Ericsson, T.; Karlsson, E.; Krozer, A.; Kasemo, B. Unusual kinetics of hydride formation in magnesium-palladium sandwiches, studied by hydrogen profiling and quartz crystal microbalance measurements. Z. Phys. Chem. 1989, 164, 1259-1260.

42. Chater, P.A.; Anderson, P.A.; Prendergast, J.W.; Walton, A.; Mann, V.S.J.; Book, D.; David, W.I.F.; Johnson, S.R.; Edwards, P.P. Synthesis and characterization of amide-borohydrides: New complex light hydrides for potential hydrogen storage. J. Alloys Compd. 2007, 446-447, 350-354.

43. Lewis, G.J.; Sachtler, J.W.A.; Low, J.J.; Lesch, D.A.; Faheem, S.A.; Dosek, P.M.; Knight, L.M.; Halloran, L.; Jensen, C.M.; Yang, J.; et al. High throughput screening of the ternary $\mathrm{LiNH}_{2}-\mathrm{MgH}_{2}-$ $\mathrm{LiBH}_{4}$ phase diagram. J. Alloys Compd. 2007, 446-447, 355-359.

44. Yang, J.; Sudik, A.; Siegel, D.J.; Halliday, D.; Drews, A.; Carter, R.O., III; Wolverton, C.; Lewis, G.J.; Sachtler, J.W.A.; Low, J.J.; et al. Hydrogen storage properties of $2 \mathrm{LiNH}_{2}+\mathrm{LiBH}_{4}+$ $\mathrm{MgH}_{2}$. J. Alloys Compd. 2007, 446-447, 345-349.

45. Chater, P.A.; David, W.I.F.; Johnson, S.R.; Edwards, P.P.; Anderson, P.A. Synthesis and crystal structure of $\mathrm{Li}_{4} \mathrm{BH}_{4}\left(\mathrm{NH}_{2}\right)_{3}$. Chem. Commun. 2006, 23, 2439-2441.

(C) 2012 by the authors; licensee MDPI, Basel, Switzerland. This article is an open access article distributed under the terms and conditions of the Creative Commons Attribution license (http://creativecommons.org/licenses/by/3.0/). 